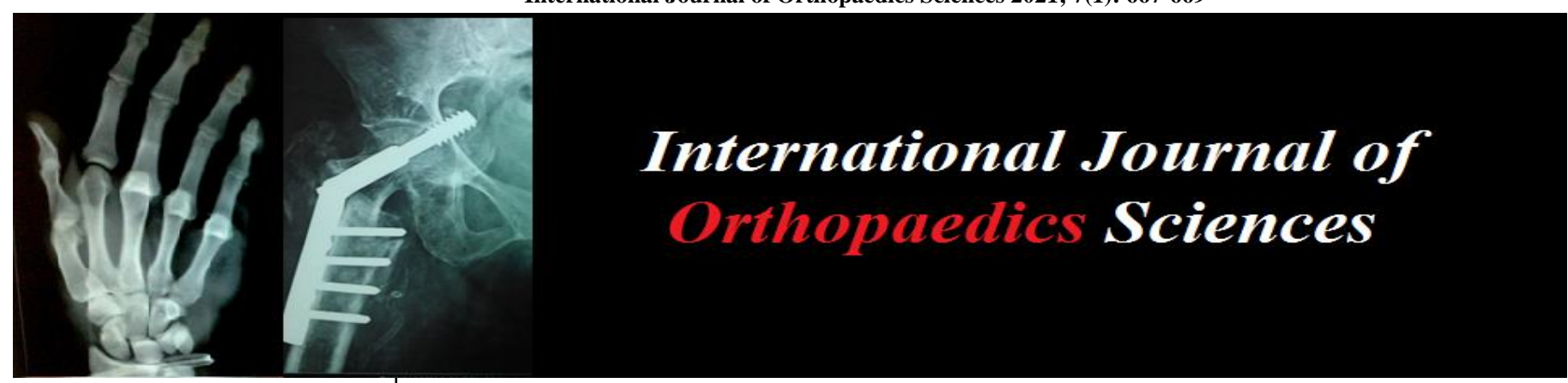

E-ISSN: 2395-1958

P-ISSN: 2706-6630

IJOS 2021; 7(1): 667-669

(C) 2021 IJOS

www.orthopaper.com

Received: 07-10-2020

Accepted: 09-12-2020

Dr. Shailesh D Ramavat

Professor, Department of

Orthopaedics, PDU Medical

College, Gujarat, India

Dr. Zalak Patel

Third Year Orthopedic, PDU

Medical College, Gujarat, India

Corresponding Author: Dr. Shailesh D Ramavat Professor, Department of Orthopaedics, PDU Medical College, Gujarat, India

\section{Results of operative management of radial head fractures by internal fixation and excision and conservative management: A study of 60 cases}

\author{
Dr. Shailesh D Ramavat and Dr. Zalak Patel
}

DOI: https://doi.org/10.22271/ortho.2021.v7.i1k.2555

Abstract

Radial head fractures are the most frequent fracture type reported around the elbow. Fractures have been documented to occur in isolation or with other associated osseous and soft tissue injuries, with awareness for the potential patterns of injury essential in determining the appropriate management to attain restoration of elbow function. Radial head fractures are seen in 33\% of elbow fractures. It may involve the radial head, radial neck or both. Treatment depends on the type of fracture, amount of displacement, comminution and associated injuries. Previously radial head excision was a popular treatment, now it is being replaced by open reduction and internal fixation or radial head replacement. The assessment of these common fractures and treatment have evolved with better understanding of the anatomy and biomechanics of radial head and the development of evidence based guidelines.

Aim and Objective: To study the clinical and functional outcome of radial head fractures managed conservatively and by mean of internal fixation and by mean of radial head excision.

Material and Methods: For prospective study Sample will be taken from the patients treated in P.D.U. Medical College and Hospital having radial head fracture on basis of plain radiograph and CT scan, classified according to Mason classification and treatment plan will be decided accordingly. Results will be assessed on basis of functional classification system at 1 month, 3 months and 6 months.

Results: In Our study of 60 cases, 30 patients having a Mason type 1 variety radial head fractures treated conservatively by mean of plaster application and 26 patients of Mason type 2 radial head fracture treated by mean of open reduction and internal fixation and 4 patient of Mason type 3 radial head fracture treated by mean of excision. Out of all the patients treated by different modality $20 \%$ of patients present with stiffness of elbow joint and $2 \%$ of patients presented with infection.

Conclusion: From our objective, functional assessment perspective open reduction internal fixation of radial head fracture when technically possible appears to be provide function superior to excision. Furthermore open reduction and internal fixation provides results similar to those obtained in less severe injuries where non-operative management is possible. Such improvement results from preservation of anatomy with maintenance of the normal load bearing characteristic of elbow joint.

Keywords: radial head fracture

\section{Introduction}

It has been estimated that fractures of the radial head account for $1.7 \%$ to $5.4 \%$ of all fractures, one third of all elbow fractures. Many questions remain regarding the epidemiology, management and outcome of these injuries Radial head fractures are the most frequent fracture type reported around the elbow. Fractures have been documented to occur in isolation or with other associated osseous and soft tissue injuries, with awareness for the potential patterns of injury essential in determining the appropriate management to attain restoration of elbow function. Diagnosis is routinely made with plain radiographs, although the use of further imaging modalities such as CT scan is increasing with an aim to better understand the injury patterns that occur. The Mason classification is the most commonly used system for classifying these injuries throughout the literature. Management includes non-operative treatment for isolated stable radial head fractures (Mason type 1), with a variety of operative techniques used for the unstable fracture patterns (Mason type 2 and type 3). Recently there has been an increased appreciation for the role of the radial head in elbow stability, the benefits and limitations of the fracture classification systems available, as well as the clinical 
relevance of associated injuries. However, despite extensive research into these injuries, controversies still exist regarding the role of further imaging modalities, the use of nonoperative management, as well as the indication and technique for operative intervention. There is a lack of prospective short and long-term patient reported outcome data for the simple isolated radial head and neck fractures, which clearly defines the indication and outcome following the nonoperative management of these injuries.

\section{Patients and Method}

The Randomized prospective study was conducted and sample was taken from patients of P.D.U. Civil Hospital, Rajkot admitted from emergency department and presenting in outpatient department. The fractures were classified under MASON classification and managed conservatively and by internal fixation and by excision. Results were assessed on the basis of functional assessment system at 1 month, 3 month, 6 month.

\section{Inclusion criteria}

Age $>15$ years to $<60$ years, Patient having closed fracture of radial head, Patient having Mason type 1, 2, and 3 fractures.

\section{Exclusion criteria}

Age <15years and age >60 years, patient who did not give consent to participate in study, Patient having other comorbid condition like Polytrauma, Patient having Mason type 4 radial head fracture require prosthetic Replacement, Patient having another pathological condition in same limb, Major Nerve and vascular injury in same limb, Pregnancy.

Standard Anteroposterior and Lateral view is mandatory in all suspected Radial head fractures. Additional Greenspan view is taken with the forearm in neutral position and the radiograph beam angled 45 degree cephalad; the following features are noted in the radiographs. Degree of impaction, Degree of angulation, presence of depression, Presence of comminution, Visualization of radiocapitellar articulation. Treatment plan is based on these features, patients treated by conservatively, internal fixation and radial head excision. Conservative treatment done by using above elbow slab or cast.

\section{Operative procedure}

Anesthesia - General or brachial plexus nerve blocks. Patient is made to lie in supine position on simple table. Intraoperatively first expose radial head and neck with a Kocher's approach. First try to reduce the partial fracture with the help of Kirschner wire, taking care not to disrupt the periosteum. If needed for improved exposure release of the origin of lateral collateral ligament. Protect the posterior interosseous nerve by pronating the forearm. Once the anatomical is reduction achived, fixation is done using Herbert screw and plate. Radial head excision is done by using same approach.

Radiological evaluation was done on 4 th week and then every month until evidence of union followed by at 6months and 1 year. The patients were evaluated with Mayo Elbow Score at the end of 6 months.

\section{Mayo elbow score}

The Mayo Elbow Performance score (MEPS) or Mayo Elbow Performance Index 248 (MEPI) is an instrument used to test the limitations, caused by pathology, of the elbow during activities of daily living (ADL). This specific test uses 4 subscales: 1. Pain, 2. Range of Motion (arc of motion of the art. humeroulnaris) 3. Stability 4. Daily Function. MEPS is a 4 part test where clinical information is rated based on a 100 points scale. $<60$ - poor 60-74 - fair 75-89 - good 90-100 excellent. PAIN 45 points-do not have pain, 30 points -mild pain, moderate pain -15 points, severe pain -0 points.

\section{Range of motion}

20 points- $>100^{\circ}$ elbow flexion, 15 points- flexion $100^{\circ}-50^{\circ}$, 5 points- $50^{\circ}$ or less.

\section{Stability}

Stable elbow-10 points. Unstable elbow-5 points. ADL (Activity of daily living) Based on 5 ADL's who are each given 5 points an image is sketched how well the patient is able to participate in the daily life. The activities are: Combing your hair performing personal hygiene Eating putting on shirt and shoes.

\section{Results and Discussion}

Mechanism of injury In our study most common cause of radial head fractures in our study population was fall from standing $(30 \%)$ followed by sports $(23 \%)$ and fall down from stairs $(10 \%)$ and motor vehicle accident $(6 \%)$ and fall from height $(6 \%)$ and twist injury (1.66\%) and direct blow(1.66\%). Sex incidence in our study out of 60 patients considered during the study, 24 were males and 36 were females. Age incidence in our study the average age of patients was found to be 40.25 years with standard deviation of 10.23 years. It typically showed a peak between 40 to 49 years. In this study youngest patient was 16 years old and oldest one was 60 years of age with majority of patients were of middle aged. Mean age of females were older than that of mean age of male. Side involvement in this study out of all the patients involved in a study $53 \%$ patient found to be involved dominant side and $47 \%$ patient appear to be involved non-dominant side of limb. Fracture classification: In our study Majority case of radial head fractures were identify as mason type 1 radial head fracture $(50 \%)$ followed by mason type 2 radial head fractures (43\%) followed by mason type 3 radial head fractures $(7 \%)$. Functional and clinical outcome: The Clinical and functional outcome is assessed by Mayo Elbow Score. In Mayo elbow score the subjective parameters of pain and activities of daily living account for $70 \%$ of the total score and the objective parameters of range of motion and stability account for $30 \%$ of the total score. A higher score (maximum, 100 points) is associated with better function and greater satisfaction, whereas a score closer to 0 is associated with greater disability. 
Table 1: Clinical and Functional outcome according to Mason type of Radial head fractures

\begin{tabular}{|c|c|c|c|c|}
\hline Outcome & Mason type 1 & Mason type 2 & Mason type 3 & Total \\
\hline \multirow{2}{*}{ Excellent $(>90)$} & 15 & 18 & 1 & 36 \\
\cline { 2 - 5 } & $(25 \%)$ & $(30 \%)$ & $(2 \%)$ & $(57 \%)$ \\
\hline \multirow{2}{*}{ Good (75-89) } & 11 & 4 & 1 & 16 \\
\cline { 2 - 5 } & $(18 \%)$ & $(7 \%)$ & $(2 \%)$ & $(27 \%)$ \\
\hline \multirow{2}{*}{ Fair $(60-74)$} & 3 & 4 & 2 & 9 \\
\cline { 2 - 5 } & $(5 \%)$ & $(7 \%)$ & $(3 \%)$ & $(15 \%)$ \\
\hline \multirow{2}{*}{ Poor $(<60)$} & 1 & 0 & 0 & 1 \\
\cline { 2 - 5 } & $(2 \%)$ & $(0 \%)$ & $(0 \%)$ & $(2 \%)$ \\
\hline \multirow{2}{*}{ Total } & 30 & 26 & 4 & 60 \\
\cline { 2 - 5 } & $(50 \%)$ & $(44 \%)$ & $(6 \%)$ & $(100 \%)$ \\
\hline
\end{tabular}

Out of all the patients of radial head fracture those who are treated with conservative management had a mean elbow score of 85.5 with SD of +12.75 which is lower than that of patients treated by open reduction and internal fixation having a mean elbow score of 92.5 with SD of +12.103 at the end of 6 months and patients treated by excision having a score of 72.5 with SD of +12.58 . Depending on that it is clearly visible that patients treated by open reduction and internal fixation having excellent clinical and functional outcome than that of those treated by conservative management. But chances of post-operative complication higher with open reduction so it is feasible to go for conservative management whenever there is radial head fracture with less severe injury because in such cases both providing same result as in conservative management there is preservation of normal weight bearing characteristic of elbow joint. But still open reduction internal fixation shows promising result than that of conservative management and excision.

Table 2: Clinical and functional outcome according to fracture management

\begin{tabular}{|c|c|c|c|}
\hline Technique & Mason type & No. of patients & Elbow score (Mean + SD) \\
\hline Conservative & Type 1 & 30 & $85.5 \pm 12.75$ \\
\hline ORIF & Type 2 & 26 & $92.5 \pm 12.10$ \\
\hline Excision & Type 3 & 4 & $72.5 \pm 12.58$ \\
\hline
\end{tabular}

\section{Complications}

In our study of 60 cases 12 patients suffering from stiffness of affected side elbow joint, out of which 10 patients were treated conservatively and one was treated by open reduction and internal fixation and one was treated with excision of radial head fracture. Other complication associated with radial head fracture treated by open reduction and internal fixation include infection, anaesthesia related complication. There is no elbow Instability or elbow dislocation post operatively.

\section{Conclusion}

From our objective, functional assessment perspective, open reduction internal fixation of radial head fracture, when technically possible appears to be provide function superior to excision. Furthermore open reduction and internal fixation provides results similar to those obtained in less severe injuries where non-operative management is possible. Such improvement results from preservation of anatomy with maintenance of the normal load bearing characteristic of elbow joint. In our study, we assess the clinical and functional outcome of different type of radial head fracture treated by different modality that's the limitation of our study.

\section{Reference}

1. Bunker T, Newman L. The Herbert differential pitch bone screw in displaced radial head fractures. Injury 1987;16:621-624. 10.1016/0020-1383(85)90011-7

2. Odenheimer $\mathrm{K}$, Harvey J. Internal fixation of fracture of the radial head. Two case reports. J Bone Jt Surg 1979;61:785-787.

3. Pearce MS, Gallannaugh SC. Mason type II radial head fractures fixed with Herbert bone screws. JR Soc Med 1996;89:340-344. 10.1177/014107689608900616

4. Ring D. Displaced, unstable fractures of the radial head: fixation vs. replacement - what is the evidence? Injury 2008;39:1329-1337. 10.1016/j.injury.2008.04.011
5. King GJ, Evans DC, Kellam JF. Open reduction and internal fixation of radial head fractures. J Orthop Trauma 1991;5:21-28. 10.1097/00005131-19910300000004

6. Ring D, Quintero J, Jupiter JB. Open reduction and internal fixation of fractures of the radial head. $\mathrm{J}$ Bone $\mathrm{Jt}$ Surg 2002;84:1811-1815.

7. Doornberg JN, Parisien R, Van Duijn PJ, Ring D. Radial head arthroplasty with a modular metal spacer to treat acute traumatic elbow instability. J Bone Jt Surg Ser A 2007;89:1075-1080. 10.2106/JBJS.E.01340

8. Van Riet RP, Van Glabbeek F, Verborgt O, Gielen J. Capitellar erosion caused by a metal radial head prosthesis: a case report. J Bone Jt Surg - Ser A 2004;86:1061-1064.

9. Kapandji IA. The Physiology of Joints 5th ed. Churchill Livingstone, Edinburgh 1982.

10. Van Reit R, Glabbeek V, Neale P, Bortier H, An K-N, O' Driscoll SW. The noncircular shape of the radial head. J Hand Surg Am 2003;28:972.

11. Jacobs JE, Kernodle HB. 1 Bone Joint Surg 1946;28:616.

12. Mcfarland B, Jeffrey CC. 1. Bone Joirint Surg 35B, 486.1 1953. Bone joint Surg 35B, P486.

13. Mason JA. Surg., Gynec. Obstet 1943;76:731.

14. Mason M. Brit. J Surg 1954;42:123.

15. Murray RC. Brit. J Surg Wagner CJ 1955 1940;28:106245. 